\title{
A Design of a Terahertz Microstrip Bandstop Filter with Defected Ground Structure
}

\author{
Arjun Kumar and M. V. Kartikeyan \\ Millimeter Wave Laboratory, Department of Electronics and Computer Engineering, Indian Institute of Technology, \\ Roorkee 247 667, India
}

Correspondence should be addressed to Arjun Kumar; akdec.iitr@gmail.com

Received 22 February 2013; Accepted 18 September 2013

Academic Editor: Krishnamachar Prasad

Copyright (C) 2013 A. Kumar and M. V. Kartikeyan. This is an open access article distributed under the Creative Commons Attribution License, which permits unrestricted use, distribution, and reproduction in any medium, provided the original work is properly cited.

\begin{abstract}
A planar microstrip terahertz $(\mathrm{THz})$ bandstop filter has been proposed with defected ground structure with high insertion loss $\left(\mathrm{S}_{21}\right)$ in a stopband of $-25.8 \mathrm{~dB}$ at $1.436 \mathrm{THz}$. The parameters of the circuit model have been extracted from the EM simulation results. A dielectric substrate of Benzocyclobutene (BCB) is used to realize a compact bandstop filter using modified hexagonal dumbbellshape defected ground structure (DB-DGS). In this paper, a defected ground structure topology is used in a $\lambda / 4,50 \Omega$ microstrip line at $\mathrm{THz}$ frequency range for compactness. No article has been reported on the microstrip line at terahertz frequency regime using DGS topology. The proposed filter can be used for sensing and detection in biomedical instruments in DNA testing. All the simulations/cosimulations are carried out using a full-wave EM simulator CST V.9 Microwave Studio, HFSS V.10, and Agilent Design Suite (ADS).
\end{abstract}

\section{Introduction}

$\mathrm{THz}$ frequency range spans from 0.1 to $10.0 \mathrm{THz}$ in the electromagnetic spectrum. This $\mathrm{THz}$ regime of EM spectrum has been effectively exploited in a variety of applications such as medical spectroscopy, security, space, imaging and measurement of overlaid dielectric substrate $[1,2]$. New trends emerging in the development of technology in optical communication systems motivate the requirement of terahertz transmission lines and components [3]. The THz technology is slowly unfolding to mature to meet needs and application specific requirements. Defected ground structures offer compact solutions for the design of microstrip antennas and other passive microwave/millimeter wave components [4]. A lot of literature is available based on defected ground structures for the size reduction of the microstrip filters [414]. However, at terahertz frequencies, no considerable work has been reported for the filter design using the defected ground structure (DGS). In this paper, a modified hexagonal dumbbell-shaped DGS/slot in the ground plane is employed in microstrip line at terahertz frequency regime to achieve bandstop characteristics. In this work, a Benzocyclobuten (BCB) substrate is used for the filter design [15].

\section{Properties of BCB Dielectric}

$\mathrm{BCB}$ is a promising organic material which is showing stable permittivity values and low loss over a broad frequency range [15]. The manufacturer [16] claims a dielectric constant $\varepsilon_{r}=2.65$, with a few percent variations between $10 \mathrm{GHz}$ and $1.5 \mathrm{THz}$, and the loss tangent of the dielectric $\mathrm{BCB}$ is also varying between 0.0008 and 0.002 within the frequency interval from $1 \mathrm{MHz}$ to $10 \mathrm{GHz}$. Additional data are also available [16] in the frequency range from $400 \mathrm{GHz}$ to $1500 \mathrm{GHz}$, which confirm a stable dielectric behavior of the $\mathrm{BCB}$ on a broad frequency range. However, no specific electrical values are provided in the middle microwave range, below $400 \mathrm{GHz}$ [17].

\section{DGS Design Studies of THz Bandstop Filter}

Various dumbbell-shaped defected ground structures (DBDGS) are shown in Figure 1; in this paper, various DB-DGS have been developed on a BCB substrate with height $(h)$ of $11 \mu \mathrm{m}$ and the permittivity $\left(\varepsilon_{r}\right)$ of the substrate is 2.6 . There are two reasons for selecting BCB as the substrate [18]. First, it is because that $\mathrm{BCB}$ can maintain the value of relative 


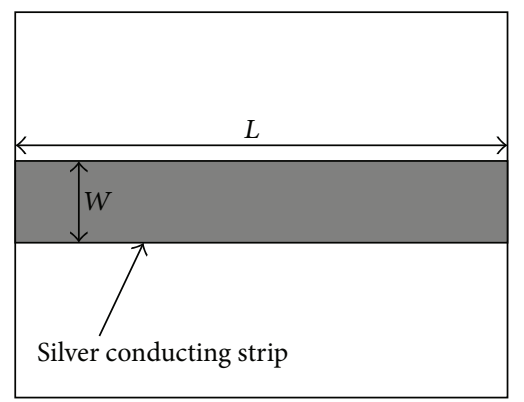

(a)

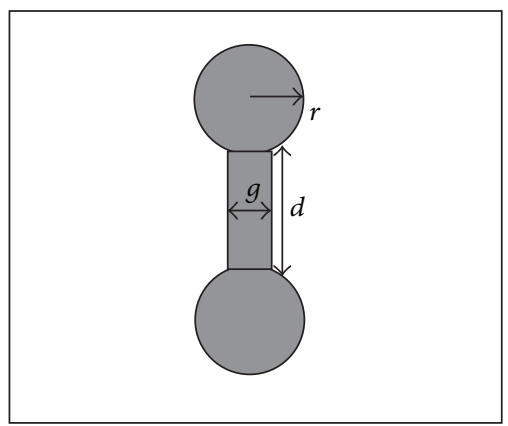

(d)

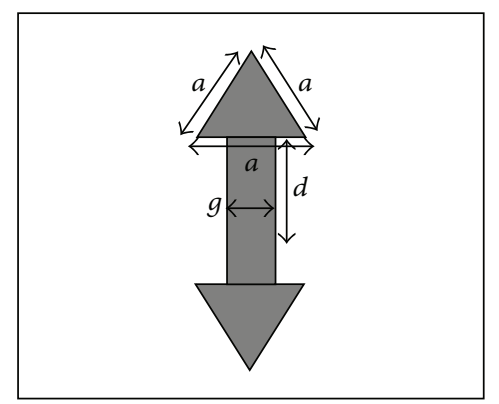

(b)

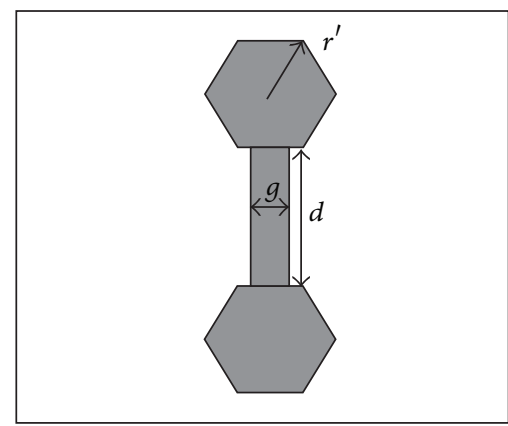

(e)

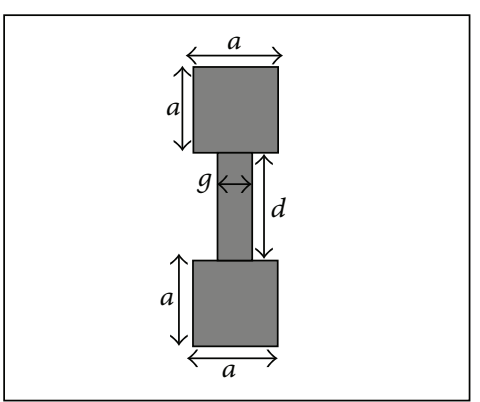

(c)

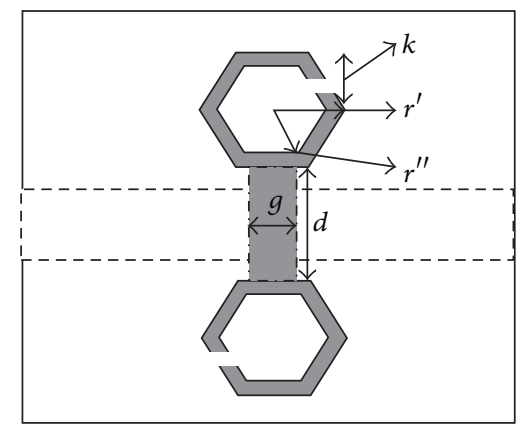

(f)

FIGURE 1: Various configurations of DB-DGS: (a) top view of microstrip line, (b) triangular DB-DGS, (c) square DB-DGS, (d) circular DBDGS, (e) hexagonal DB-DGS, and (f) modified hexagonal DB-DGS.

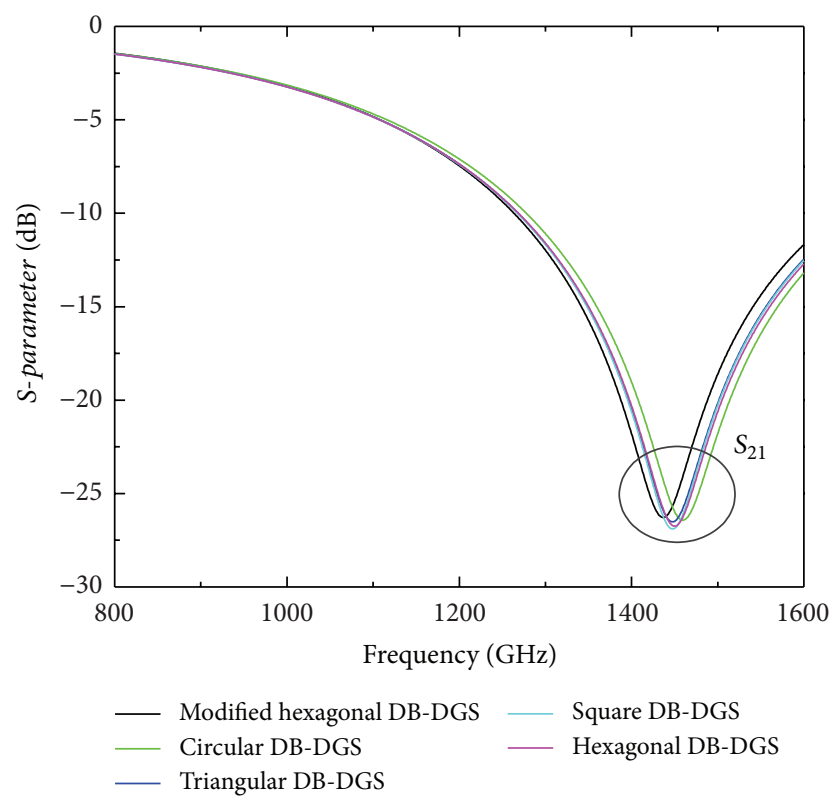

Figure 2: Comparison of simulated S-parameter of all DB-DGS [22].

permittivity in $\mathrm{THz}$ and optical radiation frequency band. Second, the dielectric loss (the part of the insertion loss) of $\mathrm{BCB}$ can be considered as zero due to almost zero value of the corresponding loss tangent $(\tan \delta)$. In this paper, the dimensions of all the DB-DGS are mentioned in Table 1 with the modified hexagonal DB-DGS with $50 \Omega$ microstrip line having width of $29 \mu \mathrm{m}$ and thickness of $0.02 \mu \mathrm{m}$. Here, the silver is used for the ground plane and the conducting strip [19].

\section{A Comparative Bandstop Characteristics of DB-DGS with the Proposed Modified Design}

All the DB-DGS that have been simulated in the CST Microwave Studio EM full-wave simulator are shown in Figure 2. The modified hexagonal indicates a more sharp transition in comparison to all other DB-DGS. It is clear from Table 2 that if the effective capacitance will increase, the sharpness of filter will increase. The 3 - $\mathrm{dB}$ cut-off frequencies for all the DB-DGS are the same; only the resonant peak will change as per configuration of DB-DGS. In Table 2, the modified hexagonal design has a more effective capacitance in comparison to other DB-DGS. This effective capacitance is responsible for the sharpness of the filter.

The values of effective inductance and effective capacitance are calculated by the circuit extraction techniques using the following formulas [5-7]:

$$
\begin{gathered}
C=\frac{5 f_{c}}{\pi\left[f_{o}^{2}-f_{c}^{2}\right]} p f, \\
L=\frac{250}{C\left(\pi f_{o}\right)^{2}} n H,
\end{gathered}
$$

Sharpness factor $=\frac{f_{c}}{f_{o}}$. 


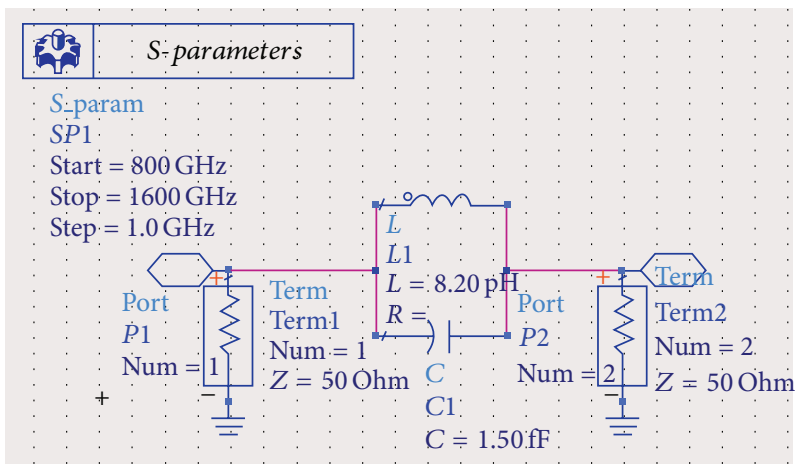

(a)

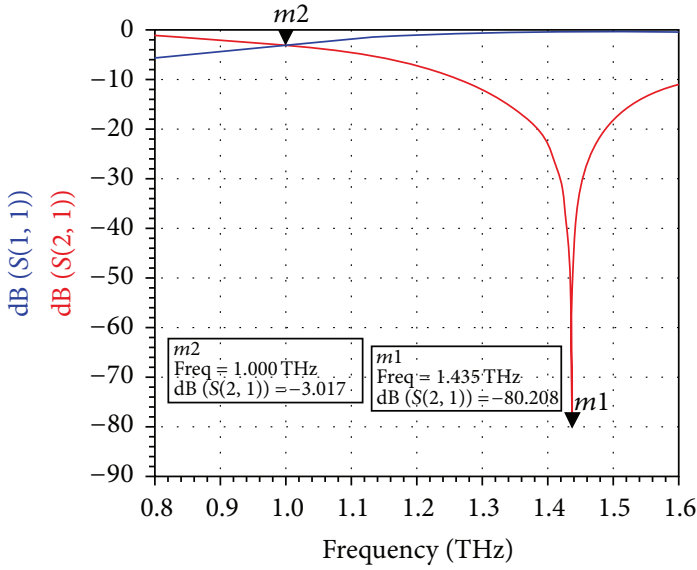

(b)

FIgURE 3: (a) L-C equivalent circuit model; (b) S-parameter characteristics by co-simulation in ADS [23].

\section{Calculation of Various Losses for the Proposed Design DB-DGS}

As the frequency increases, the losses also increase. Here, in this paper, various losses are calculated for studying the behavior of microstrip terahertz filter using a BCB substrate with height $(h)=11 \mu \mathrm{m}$, permittivity $\left(\varepsilon_{r}\right)=2.6$, width of the silver metal strip conductor $(W)=29 \mu \mathrm{m}$, thickness of strip $(t)=0.02 \mu \mathrm{m}$, and length of the conducting strip $(L)=50 \mu \mathrm{m}$. These losses are conductor loss, dielectric loss, and radiation loss which are calculated by using the formulas, given below.

Conductor Loss (see [20]). For the proposed DB-DGS in Figure 1(f), the conductor loss is 100 (nepers/meter) or $20 \mathrm{~dB} /$ meter. This is conductor loss is calculated by using (4) to $(7)[20]$ :

$$
\begin{gathered}
\alpha_{c}=\frac{R^{\prime}}{2 \cdot Z_{o}}, \\
R^{\prime}=\frac{R_{\mathrm{sh}}}{W}, \\
R_{\mathrm{sh}}=\frac{\rho}{\delta}, \\
\delta=\sqrt{\frac{2 \rho}{2 \pi f \mu_{0} \mu_{r}}},
\end{gathered}
$$

where $\alpha_{c}$ is conductor loss, $R^{\prime}$ is the resistance of entire strip, $R_{\mathrm{sh}}$ is sheet resistance of silver metal conductor, $W$ is the width of the silver metal conductor, $Z_{o}$ is characteristic impedance of line, $\delta$ is skin depth, and $\rho$ is resistivity of metal.

Dielectric Loss and Loss Tangent (see [15, 21]). The attenuation $\alpha$ at $1.4 \mathrm{THz}$ is calculated directly that is $-25.8 \mathrm{~dB}$ from the simulated $S$-parameter and $\alpha_{c}$ is calculated from (4) for silver metal. For the BCB at $1.4 \mathrm{THz}$, the dielectric loss is $5.8 \mathrm{~dB}$ and the loss tangent is 0.0002 which is calculated by using (8)

$$
\begin{gathered}
\alpha_{d}=\alpha-\alpha_{c}, \\
\tan \delta=\frac{\lambda_{o}}{\pi} \cdot \frac{\alpha_{d} \sqrt{\varepsilon_{\mathrm{eff}}}}{\varepsilon_{r}} \cdot \frac{\varepsilon_{r}-1}{\varepsilon_{\mathrm{eff}}-1}, \\
\varepsilon_{\mathrm{eff}}=\frac{\varepsilon_{r}+1}{2}+\frac{\varepsilon_{r}-1}{2}\left[1+10 \frac{h}{W}\right]^{-0.5} .
\end{gathered}
$$

Here, $\alpha_{d}$ is dielectric loss, $\tan \delta$ is loss tangent, $\varepsilon_{r}$ is relative permittivity, $\varepsilon_{\text {eff }}$ is effective permittivity, and $h$ is height of the substrate.

Radiation Loss at $1.4 \mathrm{THz}$ (see [8]). The radiation loss is calculated using simulated $S$-parameter of the proposed DBDGS that is shown in Figure 1(f). The area of the proposed filter is $87 \times 50 \mu \mathrm{m}^{2}$. Consider

$$
\eta=1-\left|S_{11}\right|^{2}-\left|S_{21}\right|^{2}
$$

Here, at $1.4 \mathrm{THz}$, the radiation loss is 0.22 or $-6.5 \mathrm{~dB}$.

\section{6. $L-C$ Modelling and Cosimulation of Proposed DB-DGS}

The $L-C$ parallel resonator circuit has been designed for the modified defect in the ground plane by the circuit extraction techniques [20]. The extracted value of inductance $(L)$ is $8.20 \times 10^{-3} \mathrm{nH}$ and the capacitance $(C)$ is $1.50 \times 10^{-3} \mathrm{pF}$ calculated by the formulas given in (1)-(2) which have been shown in Table 2. This $L-C$ model is cosimulated in ADS2006A. The simulated results are shown in Figure 3 which are in good agreement with the simulated results in CST MW Studio in Figure 4 for the modified hexagonal DB-DGS.

\section{Results and Discussion}

The extracted value of inductor and the capacitance of the simulation $S$-parameter results, the equivalent circuit model 
TABLE 1: Dimensions of various design configurations.

\begin{tabular}{|c|c|c|c|c|c|c|c|}
\hline S. no. & Design configuration of DB-DGS & $a(\mu \mathrm{m})$ & $g(\mu \mathrm{m})$ & $d(\mu \mathrm{m})$ & $r$ or $r^{\prime}(\mu \mathrm{m})$ & $r^{\prime \prime}(\mu \mathrm{m})$ & $k(\mu \mathrm{m})$ \\
\hline 1 & Circular & - & 2 & 12 & 4.6 & - & - \\
\hline 2 & Hexagonal & - & 2 & 12 & 3.1 & - & - \\
\hline 3 & Triangular & 13.1 & 2 & 12 & - & - & - \\
\hline 4 & Square & 8.2 & 2 & 11 & - & - & - \\
\hline 5 & Modified hexagonal DGS & - & 2 & 11 & 5.2 & 2.6 & 1.7 \\
\hline
\end{tabular}

TABLE 2: Dimensions of various design configurations.

\begin{tabular}{|c|c|c|c|c|c|c|}
\hline S. no. & $\begin{array}{l}\text { Design configuration } \\
\text { of DB-DGS }\end{array}$ & $\begin{array}{c}f_{c}=3-\mathrm{dB} \\
\text { cut-off }(\mathrm{GHz})\end{array}$ & $\begin{array}{c}f_{o} \text { resonant } \\
\text { frequency }(\mathrm{GHz})\end{array}$ & $\begin{array}{l}\text { Inductance } \\
(L) \text { in } \mathrm{nH}\end{array}$ & $\begin{array}{c}\text { Capacitance } \\
(C) \text { in } \mathrm{pF}\end{array}$ & $\begin{array}{l}\text { Sharpness } \\
\text { factor }\end{array}$ \\
\hline 1 & Circular & 1000 & 1458.6 & $8.43 \times 10^{-3}$ & $1.41 \times 10^{-3}$ & 0.66 \\
\hline 2 & Hexagonal & 1000 & 1447.9 & $8.34 \times 10^{-3}$ & $1.45 \times 10^{-3}$ & 0.7 \\
\hline 3 & Triangular & 1000 & 1446.1 & $8.30 \times 10^{-3}$ & $1.46 \times 10^{-3}$ & 0.71 \\
\hline 4 & Square & 1000 & 1448.8 & $8.33 \times 10^{-3}$ & $1.44 \times 10^{-3}$ & 0.72 \\
\hline 5 & Modified Hexagonal & 1000 & 1436.2 & $8.20 \times 10^{-3}$ & $1.50 \times 10^{-3}$ & 0.77 \\
\hline
\end{tabular}

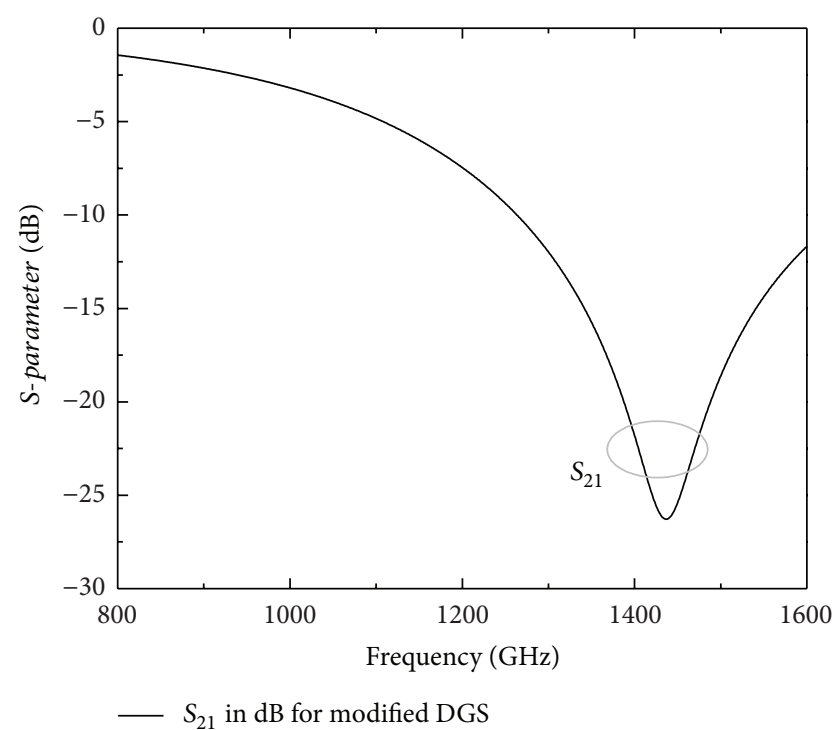

FIGURE 4: Simulated S-parameter of modified hexagonal DB-DGS [22].

of DGS is designed in ADS and again it is simulated; the simulated results of this equivalent circuit show better agreement between the simulation results of S-parameters of proposed design as shown in Figure 4; in both cases, the results are almost same. In both the CST Microwave Studio V9 and Agilent ADS2006A, the simulated results show the same cut-off frequency which is approximately $1.000 \mathrm{THz}$. At this cut-off frequency, the size of filter is in $\mu \mathrm{m}$, so the size of the proposed filter is very small and the total area of this filter is $87 \times 50 \mu \mathrm{m}^{2}$. The various losses have been calculated as insertion loss $\left(S_{21}\right)$ in stopband $-25.8 \mathrm{~dB}$, dielectric loss is $5.8 \mathrm{~dB}$, conductor loss or attenuation is $20 \mathrm{~dB} /$ meter, and radiation loss is 0.22 .

In Figure 5, the proposed modified hexagonal DB-DGS bandstop filter is cosimulated in various electromagnetic

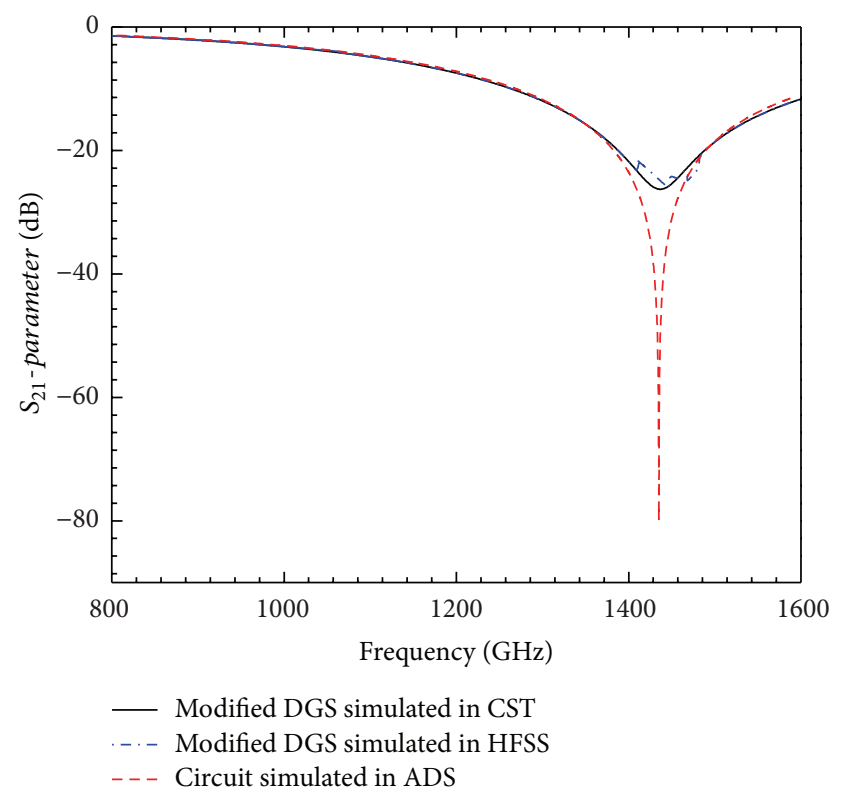

FIgURE 5: Comparison of the proposed modified DB-DGS bandstop filter in various EM simulated tools.

(EM) simulation tools for the verification and validation of the proposed filter. In all the cases, the cuto-ff frequency and resonant frequencies are almost the same. In case of HFSS simulation, the S-parameter is a little bit distorted. But in all the way, all results in EM simulation tools are in good agreement. For the simulation of proposed filter, absorbing boundary condition has been used to reduce the radiation effect.

\section{Conclusions}

Many researchers are working on $\mathrm{THz}$ filter, but no work is reported on filter design on $\mathrm{THz}$ frequency with DGS 
using microstrip. An approach is developed in this paper, and a microstrip bandstop filter has been designed at the cut-off frequency of $1.000 \mathrm{THz}$ with the insertion loss of $-25.8 \mathrm{~dB}$ at $1.4 \mathrm{THz}$ in a stopband; no stub or steppedimpedance structure is used. Only $50 \mathrm{ohm} \lambda / 4$ microstrip line with modified hexagonal-shaped DGS shows the bandstop characteristics at $1.000 \mathrm{THz}$. The simulated S-parameter is in excellent agreement with the calculated one, especially in reflection coefficient and insertion loss in both simulator CST Microwave Studio V9 and ADS200A. All the basic DB-DGS have been studied for terahertz frequency and their sharpness is compared which is shown in Table 2. The modified DBDGS is sharper than the other DB-DGS. In the literature, so far no fabrication has been reported on microstrip filter at terahertz frequency. For the validation, the proposed filter is simulated in various EM wave simulators like CST, HFSS, and ADS. After comparsion of all simulated results, it was found that the results are in good agreement.

\section{References}

[1] C. F. Kane and R. R. Krchnavek, "Benzocyclobutene optical waveguides," IEEE Photonics Technology Letters, vol. 7, no. 5, pp. 535-537, 1995.

[2] C. Wood, J. Cunningham, C. K. Tiang et al., "Measurement and simulation of the sensitivity of terahertz frequency range passive filter elements to overlaid dielectrics," in Proceedings of the 31st International Conference on Infrared and Millimeter Waves and 14th International Conference on Terahertz Electronics (IRMMW-THz'06), p. 423, Sanghai, China, September 2006.

[3] K. R. Jha and G. Singh, "Analysis of narrow terahertz microstrip transmission-line on multilayered substrate," Journal of Computational Electronics, vol. 10, no. 1-2, pp. 186-194, 2011.

[4] A. K. Arya, M. V. Kartikeyan, and A. Patnaik, "Defected ground structure in the perspective of microstrip antennas: a review," Frequenz, vol. 64, no. 5-6, pp. 79-84, 2010.

[5] C.-S. Kim, J.-S. Park, D. Ahn, and J.-B. Lim, "A novel 1-D periodic defected ground structure for planar circuits," IEEE Microwave and Wireless Components Letters, vol. 10, no. 4, pp. 131-133, 2000.

[6] J. S. Lim, C. S. Kim, Y. T. Lee, D. Ahn, and S. Nam, "A new type of low pass filter with defected ground structure," in Proceedings of the 32nd European Microwave Conference, pp. 32-36, September 2002.

[7] V. Radisic, Y. Qian, R. Coccioli, and T. Itoh, "Novel 2-D photonic bandgap structure for microstrip lines," IEEE Microwave and Guided Wave Letters, vol. 8, no. 2, pp. 69-71, 1998.

[8] H.-M. Kim and B. Lee, "Analysis of T-shaped Defected ground structure (DGS) using closed-form expressions," in Proceedings of the 3rd International Conference on Computational Electromagnetics and Its Applications (ICCEA '04), pp. 496-499, November 2004.

[9] D. Ahn, J.-S. Park, C.-S. Kim, J. Kim, Y. Qian, and T. Itoh, “A design of the low-pass filter using the novel microstrip defected ground structure," IEEE Transactions on Microwave Theory and Techniques, vol. 49, no. 1, pp. 86-93, 2001.

[10] J.-S. Lim, C.-S. Kim, Y.-T. Lee, D. Ahn, and S. Nam, "Design of lowpass filters using defected ground structure and compensated microstrip line," Electronics Letters, vol. 38, no. 22, pp. 1357-1358, 2002.
[11] A. B. Abdel-Rahman, A. K. Verma, A. Boutejdar, and A. S. Omar, "Control of bandstop response of Hi-Lo microstrip lowpass filter using slot in ground plane," IEEE Transactions on Microwave Theory and Techniques, vol. 52, no. 3, pp. 1008-1013, 2004.

[12] A. Kumar and A. K. Verma, "Design of compact seven poles low pass filter using defected ground structure," in Proceedings of the International Conference on Emerging Trends in Electronic and Photonic Devices \& Systems (ELECTRO '09), pp. 349-352, December 2009.

[13] P. Kumar, R. Mahmood, J. Kishor, and A. K. Shrivastav, "Control of band stop responses of very compact size microstrip filter of improved Q factor \& sharp transition by using hexagonal transmetal DGS," in Proceedings of the International Conference on Emerging Trends in Electronic and Photonic Devices \& Systems (ELECTRO '09), pp. 383-386, December 2009.

[14] L. H. Weng, Y. C. Guo, X. W. Shi, and X. Q. Chen, "An overview of defected ground structure," Progress in Electromagnetic Research B, vol. 7, pp. 173-189, 2008.

[15] S. Costanzo, I. Venneri, G. D. Massa, and A. Borgia, "Benzocyclobutene as Substrate Material for planar millimeter-wave structures: dielectric characterization and application," Journal of Infrared, Millimeter, and Terahertz Waves, vol. 31, no. 1, pp. 66-77, 2010.

[16] Dow Chemical. Cyclotene 3000 Series Advanced Electron Resins, http://www.dow.com/cyclotene/.

[17] S. Costanzo, A. Borgia, I. Venneri, and G. Di Massa, "Millimeter-Waves structures on benzocyclobutene dielectric substrate," Radioengineering, vol. 20, no. 4, pp. 785-789, 2011.

[18] L.-M. Si, Y. Yong, H.-J. Sun, and L. Xin, "Characterization and application of planar terahertz narrow bandpass filter with metamaterial resonators," in Proceedings of the International Workshop on Metamaterials (META '08), pp. 351-354, November 2008 .

[19] A. Hosseini, H. Nejati, and Y. Massoud, "Design of optical range third-order chebychev low-pass filter using plasmonic nanostrip waveguides," in Proceedings of the 50th Midwest Symposium on Circuits and Systems (MWSCAS '07), pp. 12451248, August 2007.

[20] E. J. Denlinger, "Losses of microstrip lines," IEEE Transactions on Microwave Theory and Techniques, vol. 28, no. 6, pp. 513-522, 1980.

[21] M. V. Schneider, "Microstrip lines for microwave integrated circuits," The Bell System Technical Journal, vol. 48, pp. 1421$1444,1969$.

[22] Agilent ADS 2006.

[23] Microwave Studio V9. 

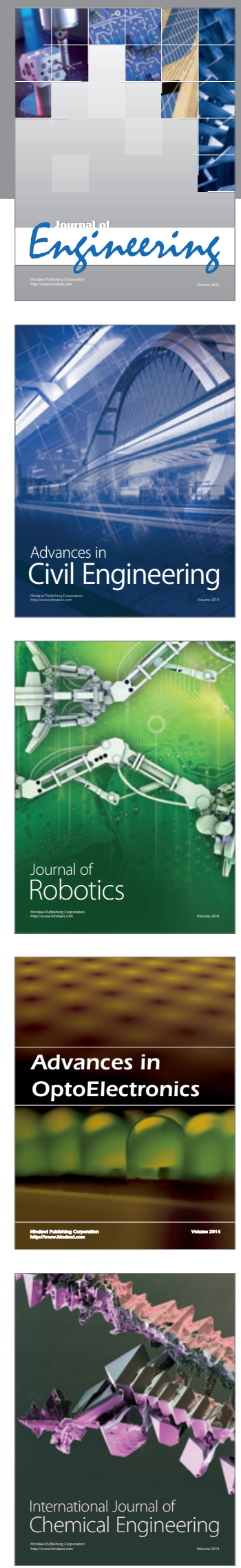

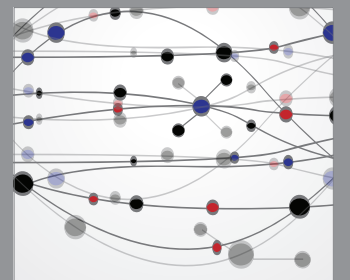

The Scientific World Journal
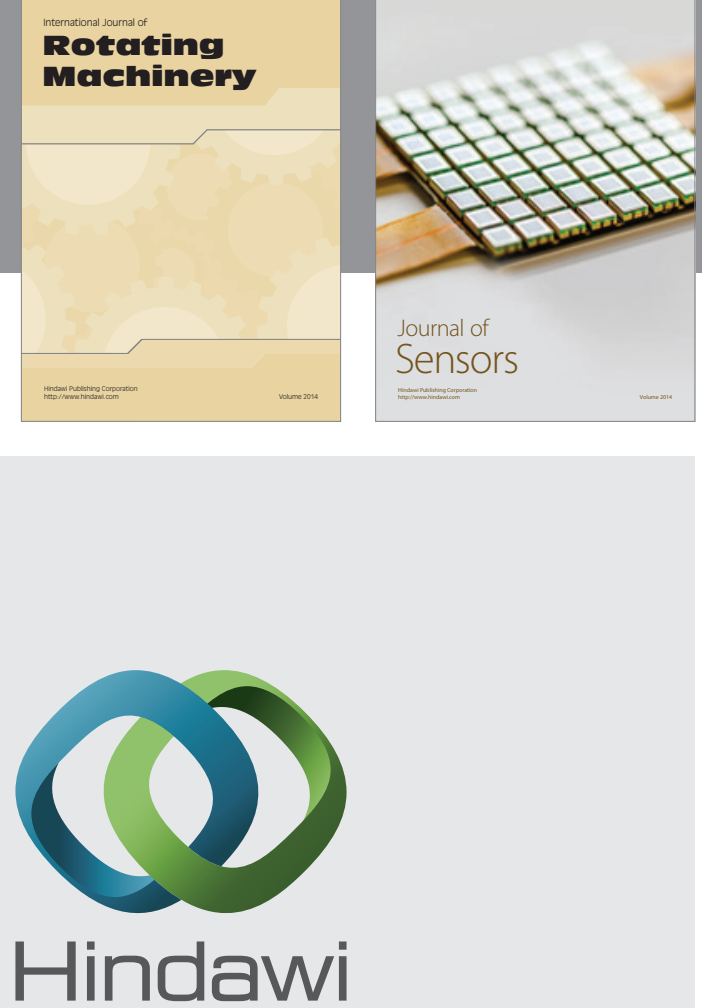

Submit your manuscripts at http://www.hindawi.com
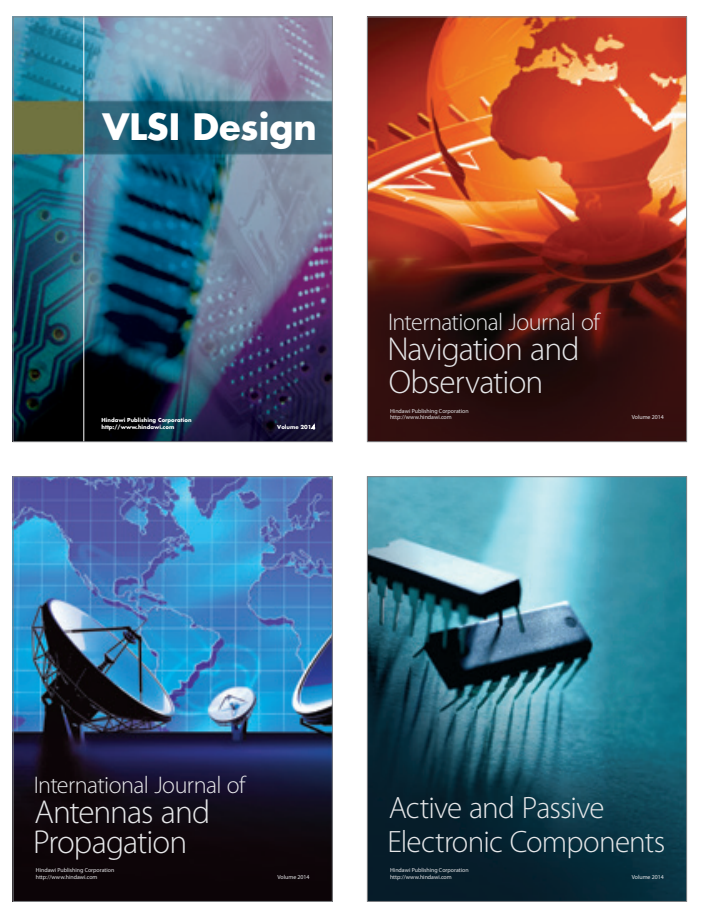
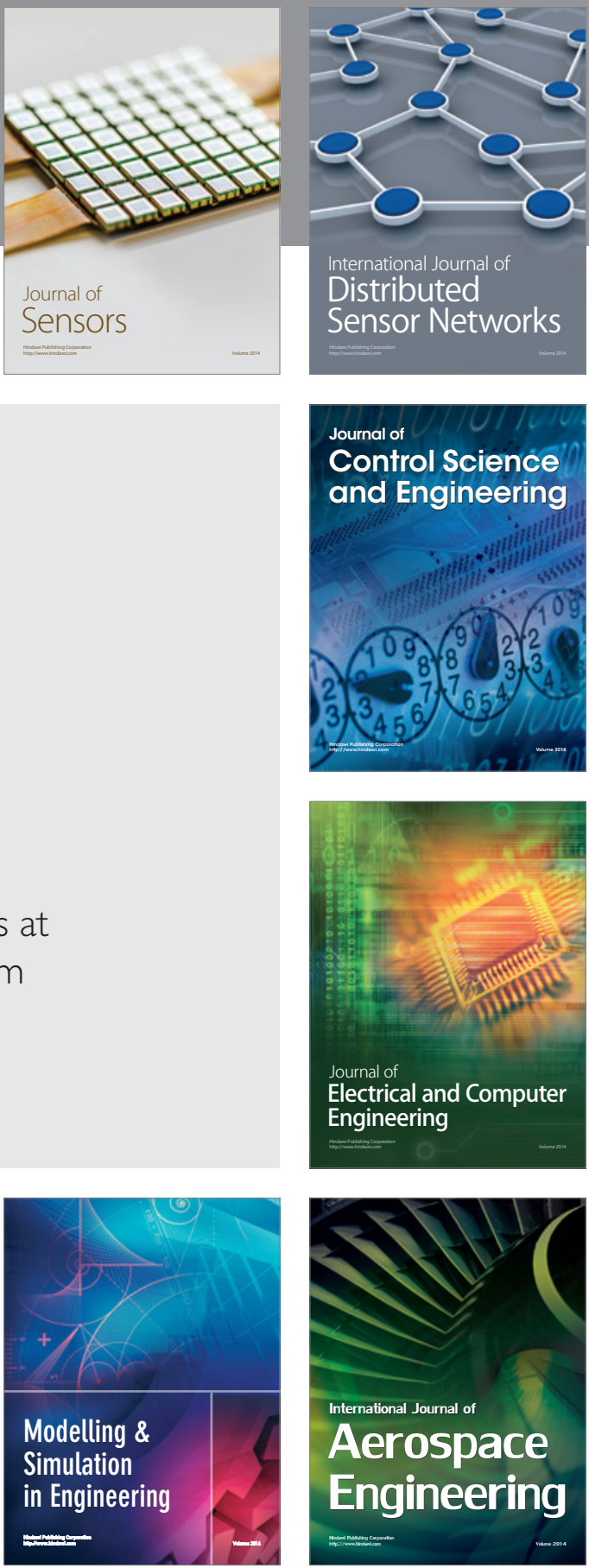

Journal of

Control Science

and Engineering
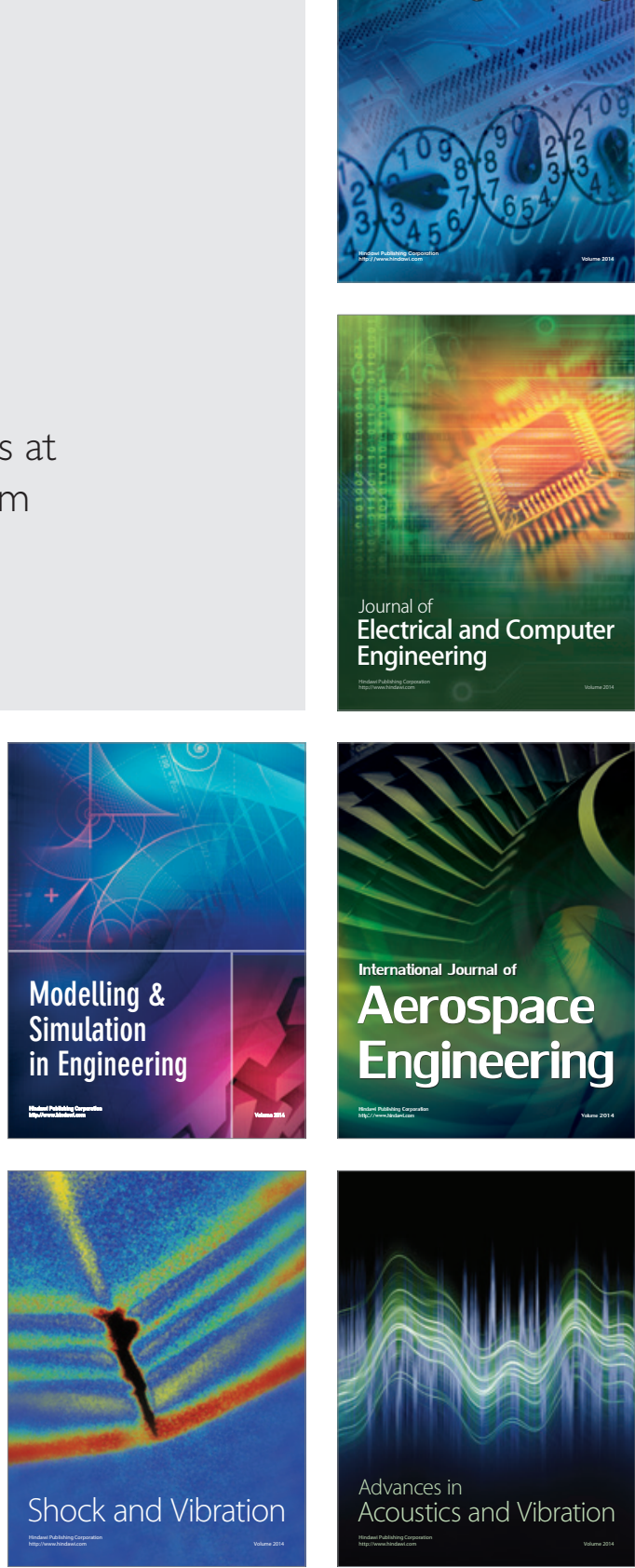